Military Technical College Kobry El-Kobbah, Cairo, Egypt

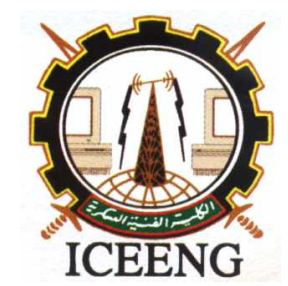

\author{
$6^{\text {th }}$ International Conference \\ on Electrical Engineering \\ ICEENG 2008
}

\title{
Investigating Coupling Between Microstrip Antennas as a Mine Detection Technique
}

\author{
By
}

Mohamed H. Abd ElAzeem*

\section{Abstract:}

The analysis and study of mutual coupling between two opposite microstrip antennas help to investigate an efficient method for mine detection technique. The study involves the effect of relative distance between two patches on the level of the mutual coupling between them. Then the effect of placing a dielectric media above the antenna system (to avoid the effective dielectric constant phenomenon), the system is then put over two materials in order to judge (in an approximate manner), the effect of these materials on the coupling level. Recording these responses, the effect of buried objects will clearly appear as it will affect the previous coupling level received by the receiving antenna. These results can be followed in steps to be applied as a mine detection technique. The antenna system was fabricated, measured and the results were compared with the simulations using both MoM, TLM numerical techniques.

\section{Keywords:}

Microstrip antenna, Mutual coupling, Numerical Techniques. 


\section{Introduction:}

The design procedure needed for a prototype of a mine detection system follows the next steps: Designing two oppositely microstrip patches, in order to make the patches system independent on $\left(\varepsilon_{\text {reff }}\right)$, another layer of the same dielectric constant $\left(\varepsilon_{\mathrm{r}}\right)$ will cover the system, now the system is stable at a certain frequency (which is the proposed one), the distance between the two elements is then optimized for best separation. Mines mainly planted in sandy or dry soil lands, thus the study will mainly handle these materials. Finally, inserting object of standard shape will be studied.

All these steps will be handled in three ways, empirically fabricated and measured then by simulation using both MoM and TLM (TLM algorithm made by the author).

\section{Basic Microstrip Antenna System:}

The investigated E-plane coupled microstrip patch antenna array system described in $[1,2]$ (resonating at $7.5 \mathrm{GHz}$ ) was partially changed in order to match the available substrate in order to fabricate and measure the system.

The microstrip patches are made over RT Duroid 5880 substrate (dielectric constant $\left.\varepsilon_{\mathrm{r}}=2.2\right)$ with height $(\mathrm{h}=0.508 \mathrm{~mm})$. Based on the microstrip antenna design equation stated in [3] and for keeping the same resonant frequency, the dimensions were slightly different, and the feeding point was changed too. Figure (1) shows the model of the patches system. The system dimensions are as follows, $a=12.6 \mathrm{~mm}, \quad b=6 \mathrm{~mm}$, $\mathrm{x}=7.075 \mathrm{~mm}, \mathrm{w}=1.05 \mathrm{~mm}, \mathrm{~d}=1.58 \mathrm{~mm}, \varepsilon_{\mathrm{r} 1}=\varepsilon_{\mathrm{r} 2}=2.2$, and $\mathrm{O}_{1}, \mathrm{O}_{2}$ are the feeding and observation points. Figure (2) shows the fabricated patch array antenna system.

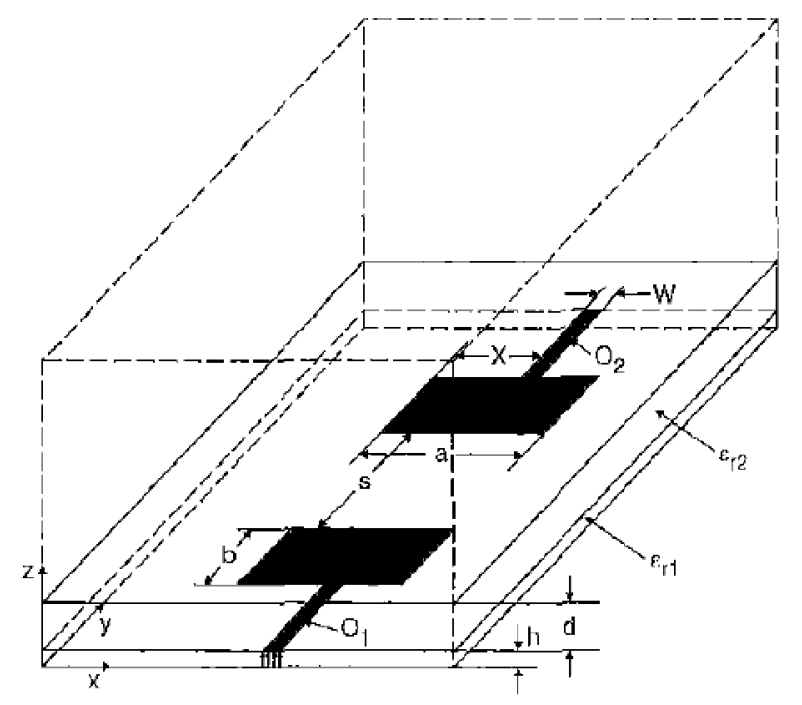

Figure: (1) Model of the microstrip patch antenna system 

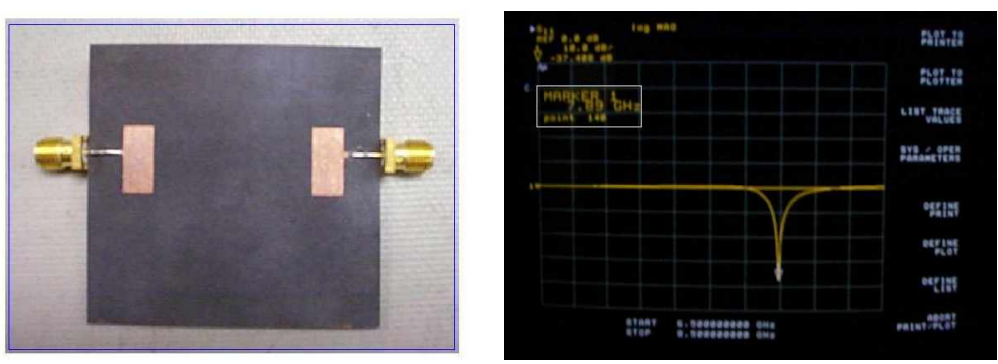

Figure: (2) Fabricated patch array antenna system, snapshots of measured $S_{11}$

Figures $(3,4)$ show the response of the fabricated antenna system before putting the dielectric cover. The results of the fabricated system and simulations show good matching.

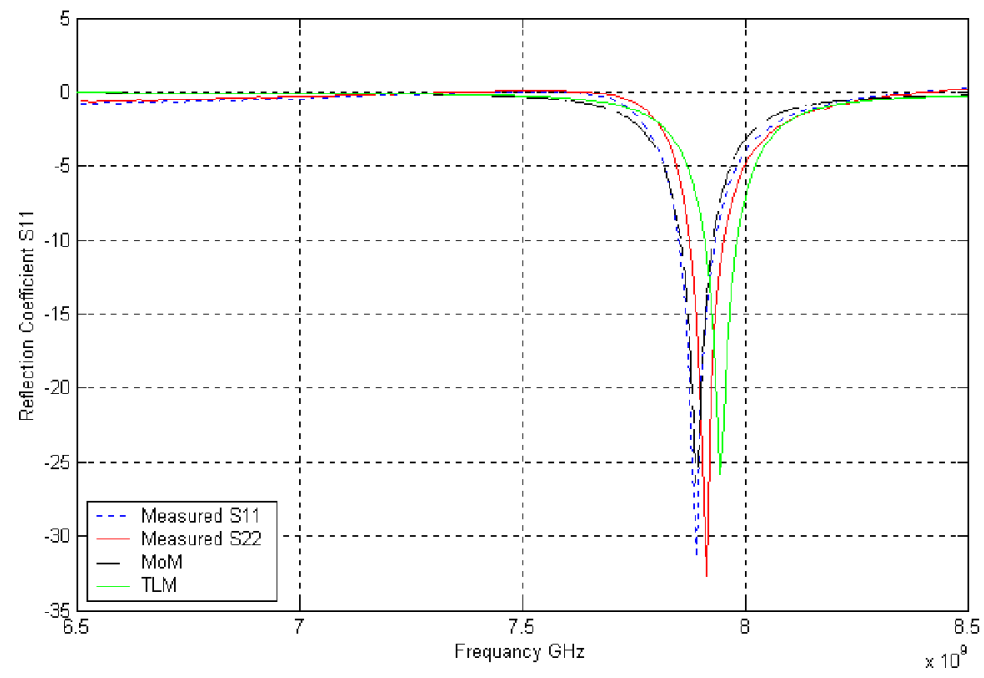

Figure: (3) Measured, MoM and TLM reflection coefficient

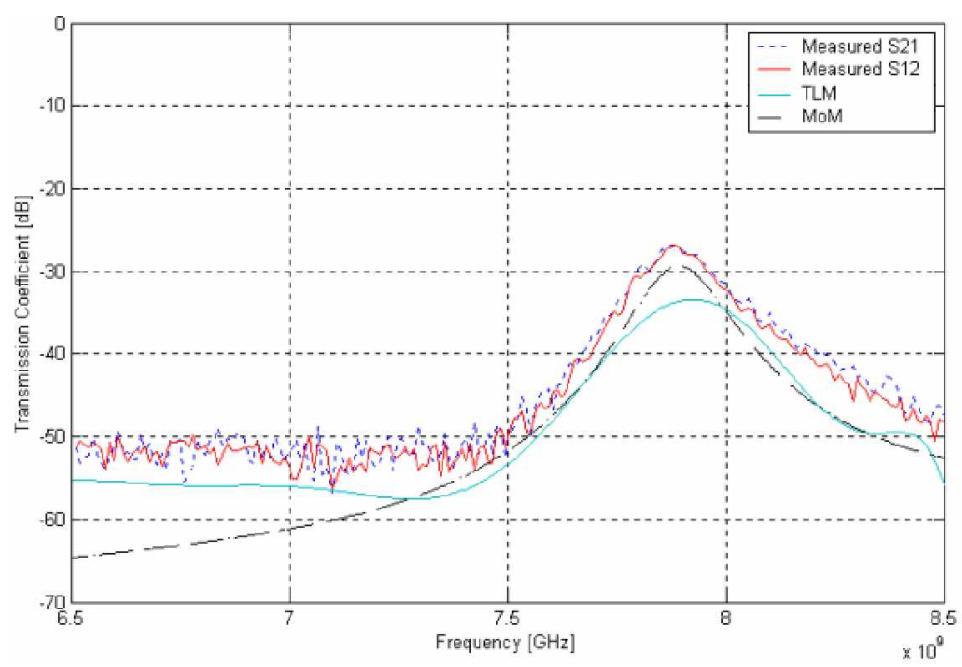

Figure: (4) Measured, MoM and TLM transmission coefficient 


\section{Covered Microstrip Antenna System:}

It is known that the resonant frequency of the microstrip antenna is affected by the relative dielectric constant of the substrate, and due to the nonhomogeneity between substrate and the free space, an (effective) relative dielectric constant is formed $\left(1 \leq \varepsilon_{\text {reff }}\right.$ $\leq \varepsilon_{\mathrm{r}}$ ) as shown in Figure (5), and the resonance frequency is now alternated as the system moves from place to other depending on the surrounding $\left(\varepsilon_{\mathrm{r}}\right)$. In order to make the resonant frequency of the array system independent on the environment properties, another layer of the same substrate (same $\varepsilon_{\mathrm{r}}$ ) with sufficient height is added above the structure and hence the system has nearly a constant $\left(\varepsilon_{\mathrm{r}}\right)$ and thus the resonance frequency is stable at the designed one $(7.5 \mathrm{GHz})$.
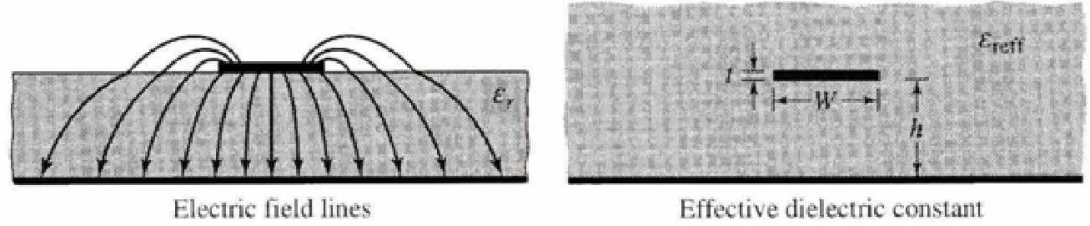

Figure: (5) Formation of the effective dielectric constant

Also, surface waves are excited in microstrip antennas whenever the substrate has mismatching $\left(\varepsilon_{\mathrm{r}}>1\right)$. Besides end fire radiation, surface waves give rise to coupling between the two E-plane coupled antenna elements affecting the radiation pattern and input VSWR. If the antenna system is covered by a typical layer of the same $\varepsilon_{\mathrm{r}}$, surface waves will meet matched layer instead of reflecting interface, this will degrade it. If the separation is maintained so that the coupling is less than (20dB), the gain and VSWR will not not be degraded [4].

The optimization of the distance between the two oppositely antennas was selected ( 3 $\mathrm{cm})$ such that the reflection coefficient be independent on the distance between them and the transmission coefficient is relatively sufficient (not too small to be able to discuss its variations with respect to ground beneath and effect of buried objects). Figure (6) shows the performance of the patch system after placing the cover and changing the distance between the antennas, taking $\mathrm{s}=1,2,3,4,5,6$ and $7 \mathrm{~cm}$ as these distances are considered ratios of the wavelength.

It can be noted that at $s / \lambda=0.75$, the reflection coefficient is in steady state condition, while the transmission coefficient is suitable, while Figure (7) shows the comparison of the mutual coupling level between the simulation results with the measured data. 


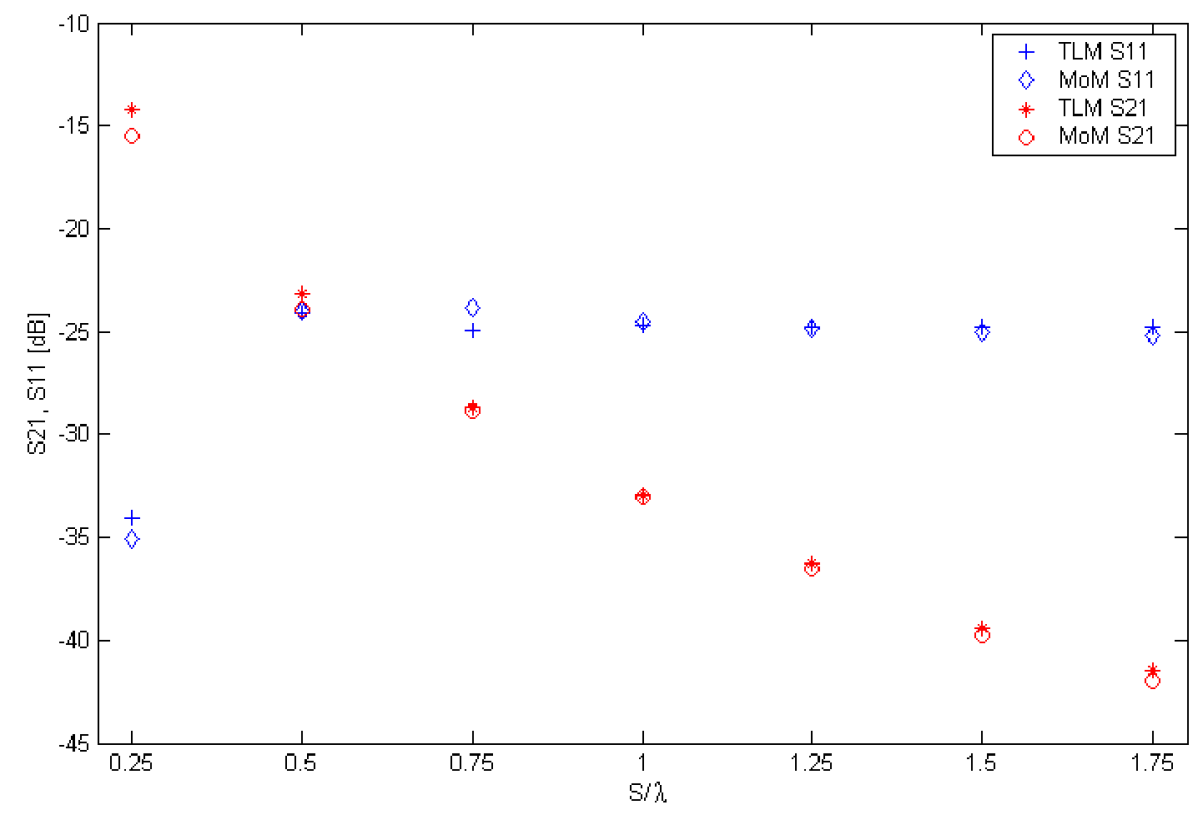

Figure: (6) Transmission and reflection coefficients against spacing $(s / \lambda)$

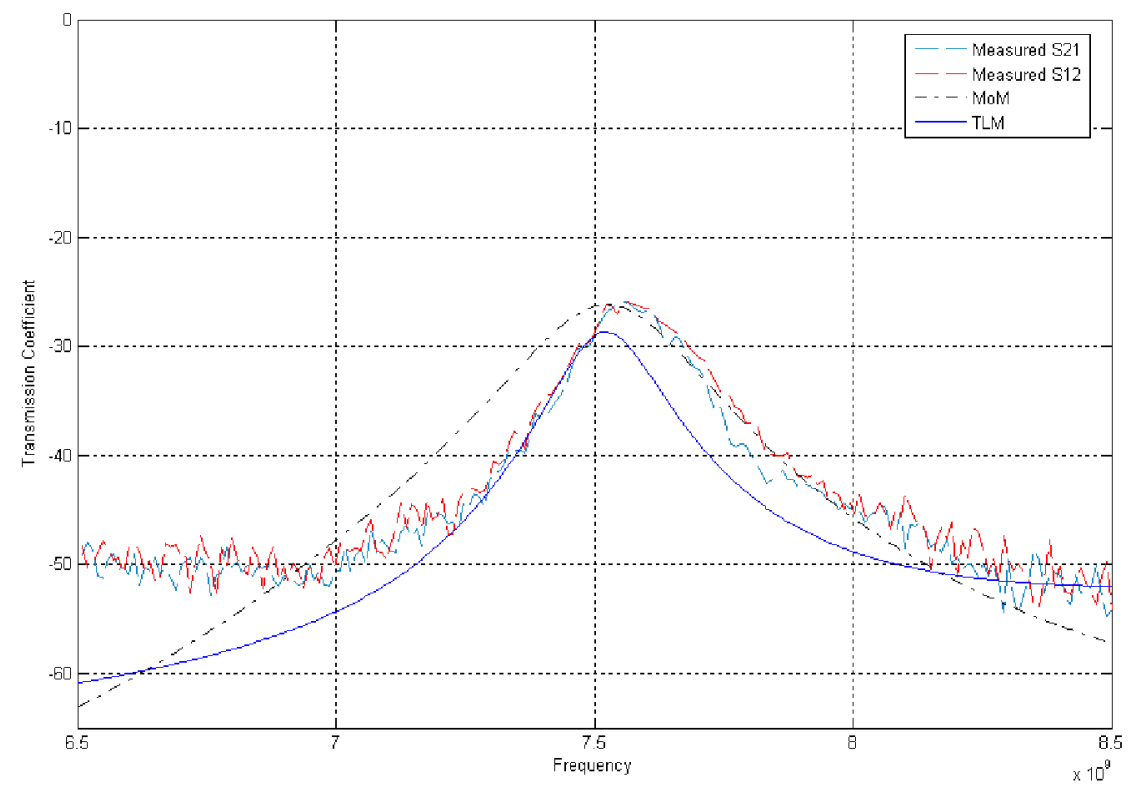

Figure: (7) Measured, MoM and TLM simulation results at $s / \lambda=0.75$

\section{Effect of Both Ground Material and Buried Object:}

Mines usually buried either in sandy lands or in dry soils. Thus the investigation of material effect will handle theses cases, free of mines firstly, then putting the mine and comparing the difference between the two levels indicates the existence of an object. In order to consider the ground beneath the antenna system infinite (homogenous ), and thus assure the homogeneity of field lines propagation in the ground material, the 
thickness (depth) of this ground should be in the order of about $(10 \lambda)$ of the operating frequency [5]. Figure (8) shows the mechanism of coupling between the two antenna systems with and without the target. The study is done for the object chosen is a cube of copper (of side $1 \mathrm{~cm}$ ).

\section{Antenna over Sand}

Ideally, sand (or $\mathrm{Sio}_{2}$ ) has a dielectric constant of typical value about $\left(\varepsilon_{\mathrm{r}}=3-5\right)$ with $(\tan \delta=0.00075)$. Figure (9) shows the coupling level after putting the system over the sand sample, as compared between measured and simulation. The gain in coupling effect between the two cases (with sand and without sand) may be explained by that the dielectric constant of the sand (considered for best simulation results to be 3 ) is very near to the cover substrate dielectric constant (2.2), and hence waves undergo small reflections at that interface and most of the power is linked (coupled) to the receiver.

Finally, an increase of the coupling level of about $(9 \mathrm{~dB})$ is observed when the antenna system over sand ground placed over a mine. Figure (10) shows the comparison of available data. Simulation data shows good matching, in spite of slight differences between the measured, MoM and TLM simulations which can be explained in two ways; firstly, the TLM approximates the conductivity of the target copper material to be infinite and thus the reflection over the cube (target) is assumed perfect (simulated with reflection coefficient $\Gamma=-1$ ). Secondly, in both simulation (MoM, TLM), the relative dielectric constant is taken ideally to be of value (3), which is surly differs from the practical sample of sand taken. Figure (13), shows the results of the mutual coupling when the antenna system is over the mine body. Figure (11) shows snapshot of measured data (system over a mine) using (HP 8510c) vector network analyzer.

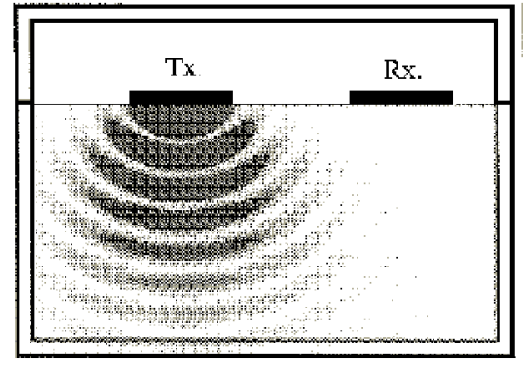

(a)

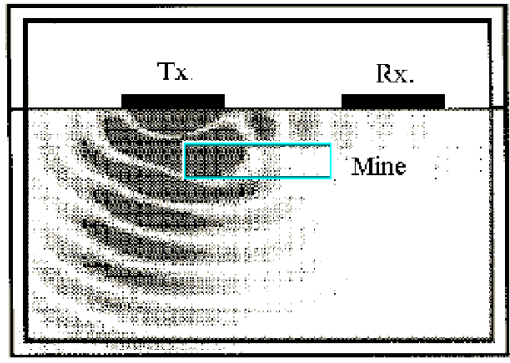

(b)

Figure: (8) Mechanism of mutual coupling with and without mine 


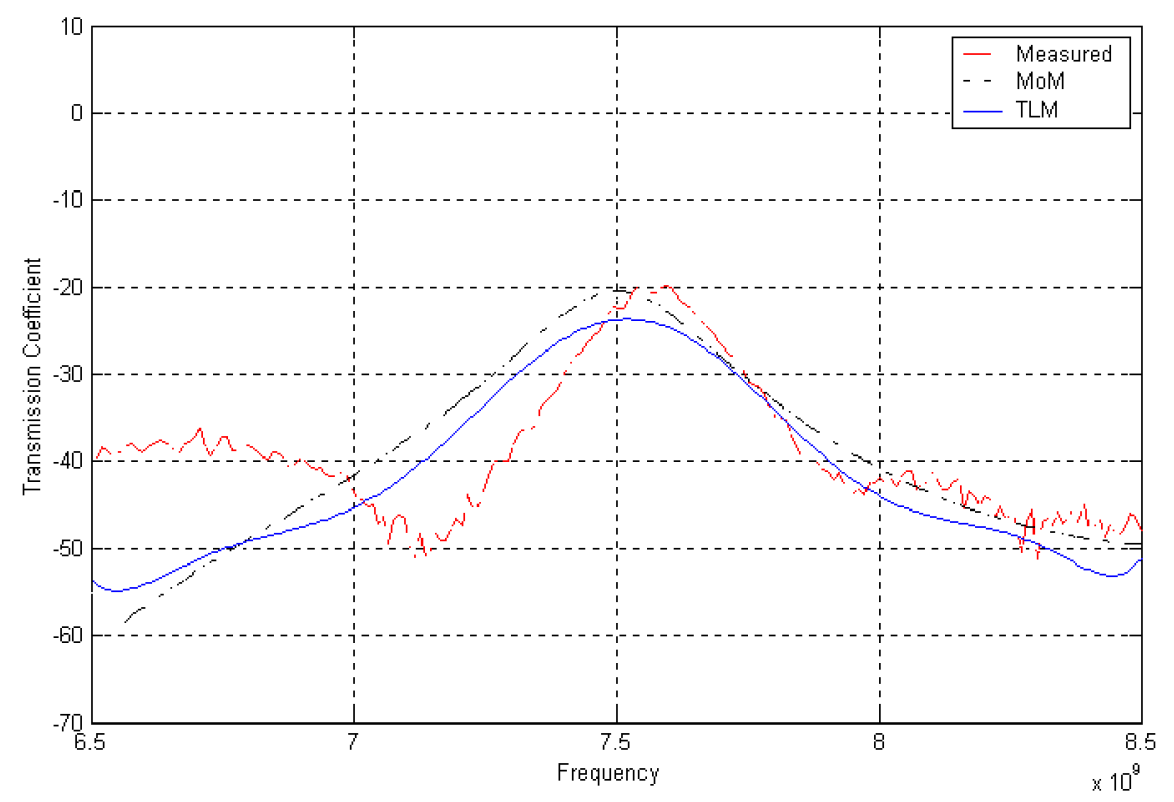

Figure: (9) Measured, MoM and TLM simulation results for the system over sand

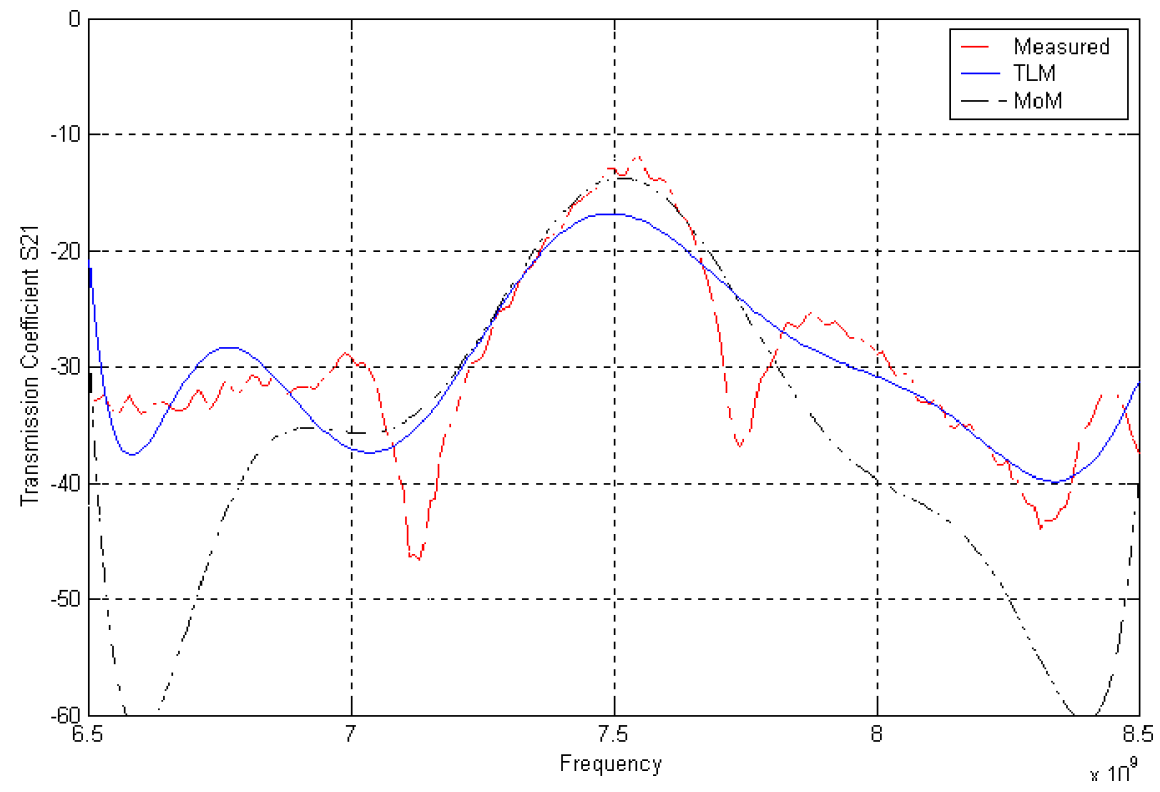

Figure: (10) Measured, MoM and TLM simulation results for the system over mine 


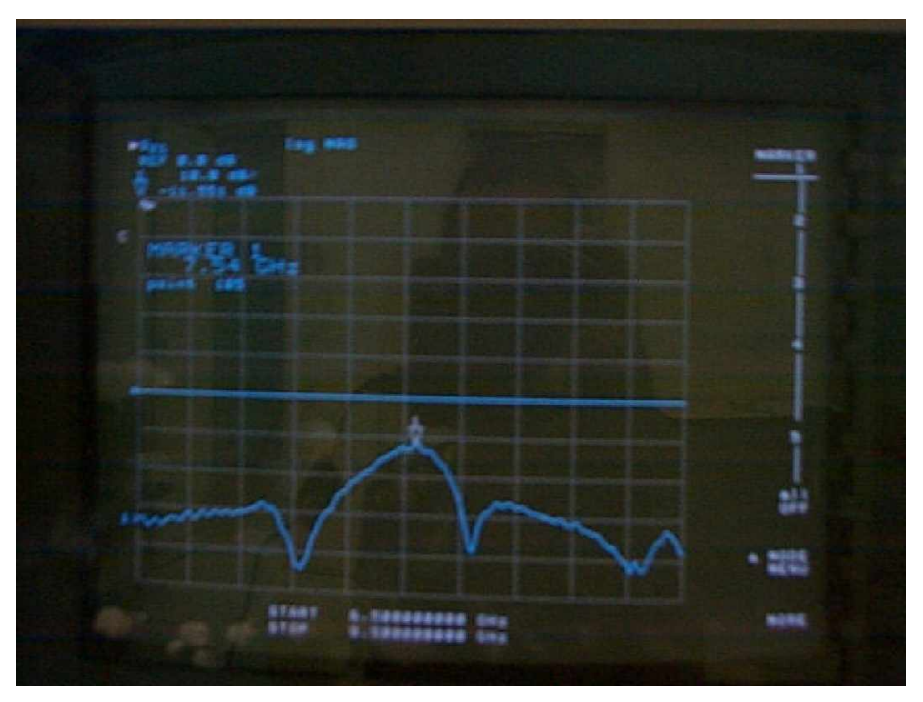

Figure: (11) Snapshot of measured $S_{21}$ when the antenna system is above a mine

In order to consider these results accurate, the reflection coefficient should remain constant in all cases, hence the transmission level variation is only function of the surrounding environment properties. Figure (12) shows snapshots of the $\left(S_{11}\right)$ in the three possible cases (antenna over free space, antenna over sand and system over mine). Difference between the two first cases is about $(3 \mathrm{~dB})$, while when the system is placed over ground, only $(1 \mathrm{~dB})$ difference is noticed.
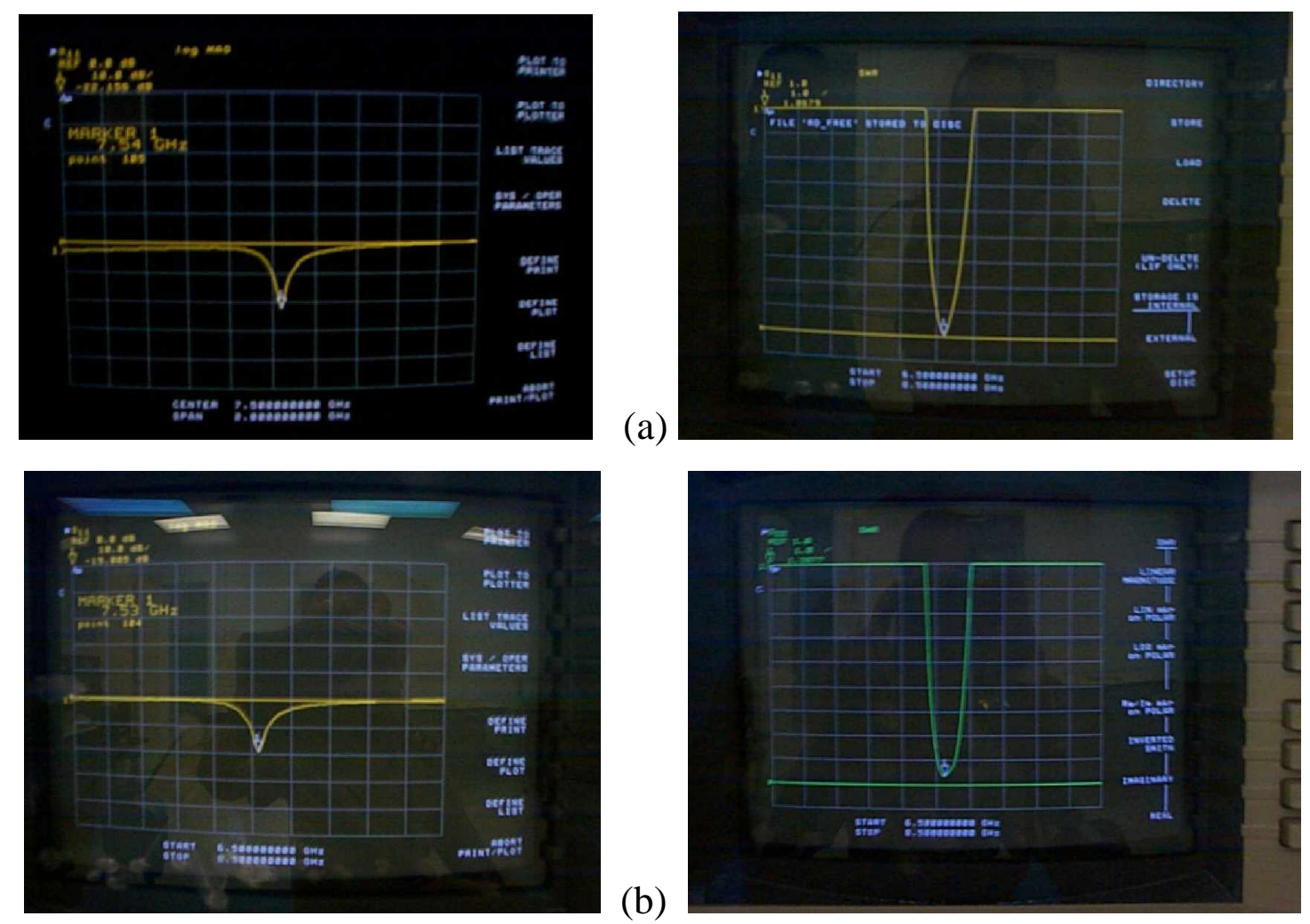

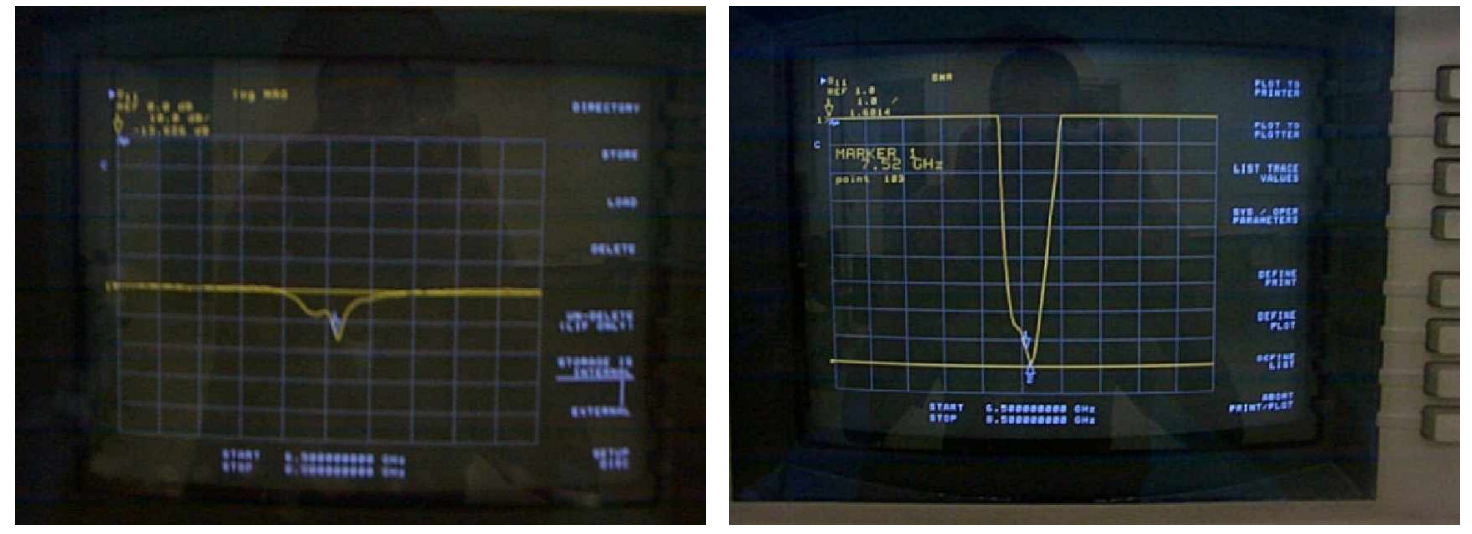

(c)

Figure: (12) (a) antenna over free space, (b) antenna over sand (c) system over mine. Left column is the $S_{11}$ and the right column is its corresponding VSWR

\section{Antenna over Dry Soil}

Although the relative dielectric constant of the dry soil is approximately (2.8) which is nearby to (2.2) of the substrate, but the coupling effect decreased about $(-10 \mathrm{~dB})$ when placed over dry soil (Figure 13). This can be related to the loss tangent of this material $(\tan \delta \approx 0.05)$ which indeed affect the wave propagation inside it and cause faster decay than that happened on the sand case, note that; the loss tangent in the simulation data give best approximations for $(\tan \delta \approx 0.1)$.

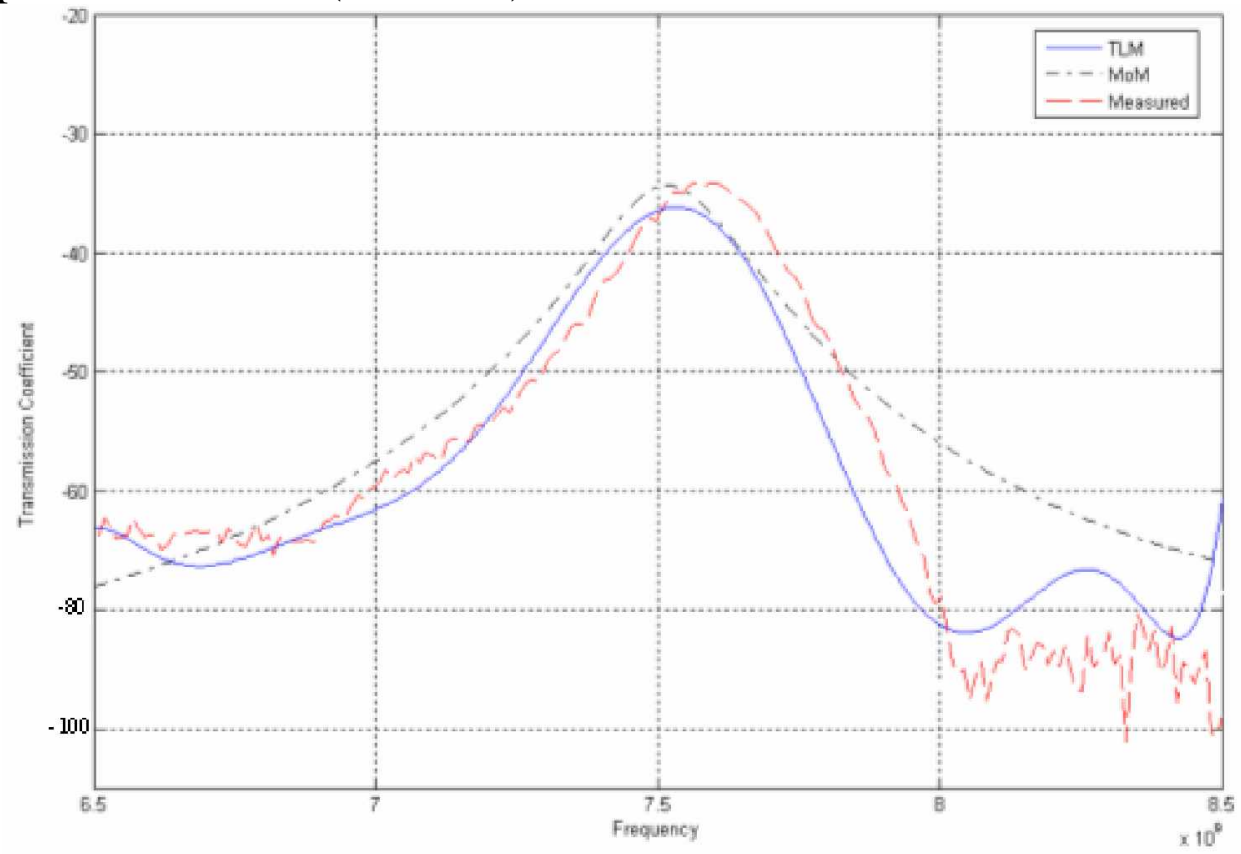

Figure: (13) Measured, MoM and TLM results over dry soil 
Placing the target under the system and measuring the transmission coefficient yields to a significant increase about $(12 \mathrm{~dB})$ as shown in Figure (14).

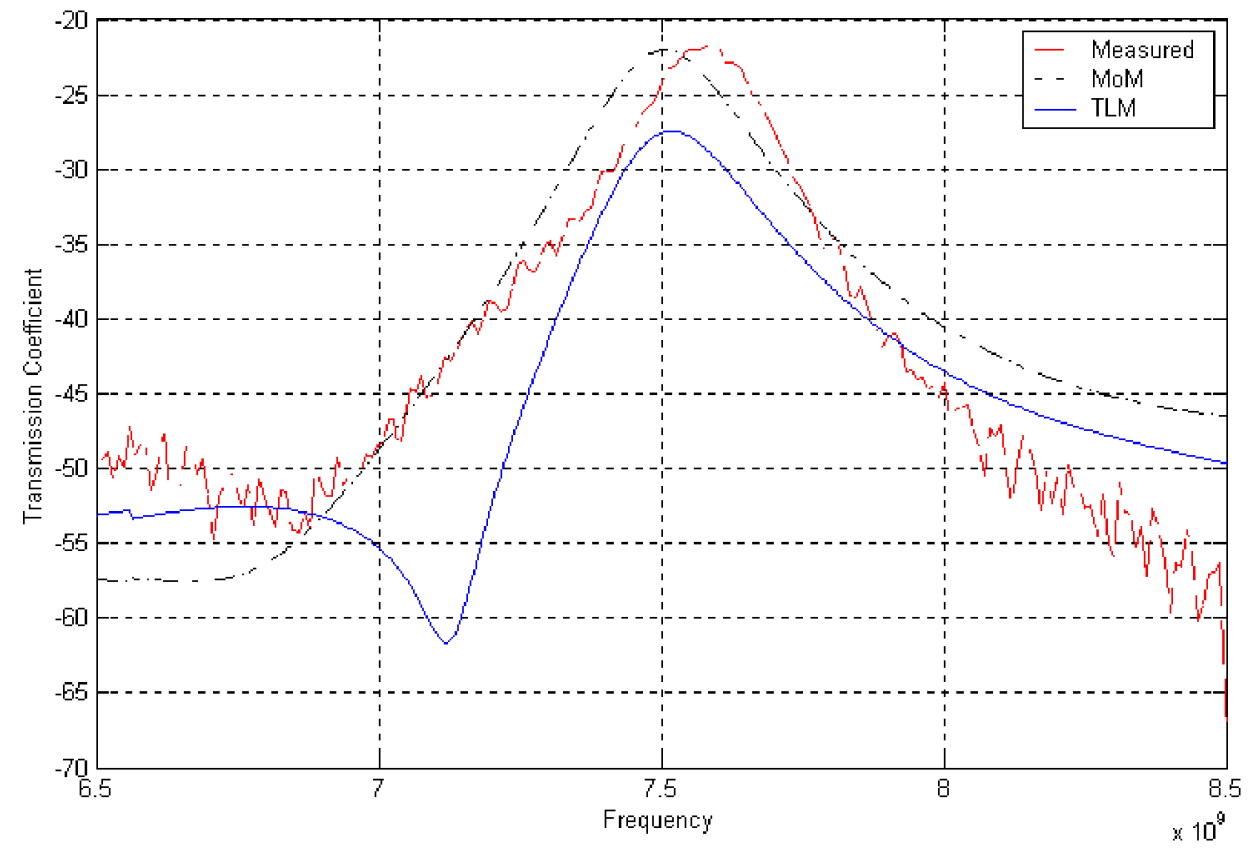

Figure: (14) Measured, MoM and TLM results over mine

\section{Conclusions:}

A prototype system operating at $(7.5 \mathrm{GHz})$ is fabricated and the detection is based on measuring the difference between the levels of the coupling between the two antennas. Starting by locating the antenna system in free space, the coupling level is $(-25 \mathrm{~dB})$. The system is then put over a sandy land and a coupling level of $(-20 \mathrm{~dB})$ is noticed. When the system is placed over a metallic body of $\left(1 \mathrm{~cm}^{3}\right)$ volume hidden inside this sand, the coupling level reaches $(-11 \mathrm{~dB})$ increasing about $(9 \mathrm{~dB})$. The study is then repeated for the dry soil and the initial indication of the system over that soil was $(-35 \mathrm{~dB})$, when the antennas put over the metallic body the level increases to be $(-23 \mathrm{~dB})(12 \mathrm{~dB}$ increase is noticed). The increase in coupling level is used to indicate the presence of buried objects. The fabricated system showed clear differences between mutual coupling levels and the simulation results supported these results in a good synchronization. 


\section{References:}

[1] A. Benalla and K. C. Gupta, "Mutual Coupling between Rectangular Microstrip Patches Covered with a Dielectric Cover Layer", IEEE Antennas \& Propagation Int. Symposium, May 1990, pp.385-361.

[2] S. Yang, I. G. Gosling, S. H. Tan and M. G. Sorwar, "TLM analysis of the Mutual Coupling of Microstrip Patch Antenna Arrays", IEE Proc. Microwave, Antennas Propag., vol. 147, no. 3, June 2000.

[3] Constantine A. Balanis, "Antenna Thoery". John Wiely \& Sons.

[4] Ramesh Garg, Prakash Bnartia, Inder Bahl and Apisak Ittipiboon, "Microstrip Antenna Design Handbook", Artech House, 2001.

[5] Ian G. Gosling and Pingyu Qu, "Propagation Characteristics of a Heavyside Absorbing Layer for TLM”, IEEE Trans. MTT, vol. 45, no., 2, Feb. 1997. 